\title{
Real-World Drug Costs of Treating Hepatitis C Genotypes 1-4 with Direct-Acting Antivirals: Initiating Treatment at Fibrosis 0-2 and 3-4
}

\author{
Timothy A. Bach, PharmD, and Kathy Zaiken, PharmD
}

\begin{abstract}
BACKGROUND: Direct-acting antivirals (DAA) for the treatment of hepatitis $C$ virus (HCV) have drastically improved outcomes but are also very costly. For this reason, priority for treatment is often given to patients with a higher fibrosis score at baseline by payers and providers rather than treating all eligible patients. Simulation studies have suggested that waiting to treat patients until fibrosis 3-4 may be more costly and result in worse outcomes; however, real-world implications are unknown.
\end{abstract}

OBJECTIVE: To determine drug costs and outcomes for treating hepatitis $\mathrm{C}$ in patients with fibrosis scores of 0-2 and 3-4 at baseline in a real-world ambulatory care setting.

METHODS: A total of 322 patients at 36 clinical sites in Massachusetts with HCV genotype 1-4 and a prescription for at least 1 DAA medication between May 2011 and October 2015 were included. Retrospective and prospective chart reviews were completed by the primary investigator. Data were collected through April 2016. The primary outcome for the study was to determine the mean drug cost per sustained virologic response (SVR) achieved for patients with fibrosis scores of 0-2 and 3-4. Drug costs were calculated using average wholesale price and only included the cost of HCV medications, not for adjunctive medications, blood work, hospitalizations, anticipated complications, or any other projected medical costs.

RESULTS: The mean \pm SD (median) drug cost per patient was $\$ 130,391 \pm 46,787(113,400)$ and completed treatment duration was $15.0 \pm 8.9$ (12) weeks. The mean drug cost per SVR was $\$ 155,662$ for all patients with a mean drug cost per SVR of $\$ 122,452$ and $\$ 178,401$ for patients with fibrosis scores of 0-2 and 3-4, respectively. SVR rates were $83.5 \%(269 / 322)$ for all patients and $92.2 \%(107 / 116)$ and $78.6 \%(162 / 206)$ for patients with fibrosis scores of 0-2 and 3-4, respectively. Ledipasvir/ sofosbuvir; sofosbuvir + ribavirin; ledipasvir/sofosbuvir + ribavirin; sofosbuvir + interferon + ribavirin; boceprevir + interferon + ribavirin; sofosbuvir + simeprevir; and telaprevir + interferon + ribavirin had a mean drug cost per SVR of $\$ 123,559 ; \$ 153,347 ; \$ 157,969 ; \$ 184,800 ; \$ 248,640 ; \$ 251,550$; and $\$ 373,333$; respectively.

CONCLUSIONS: Real-world knowledge about outcomes and drug costs may influence future decisions. Further studies are needed to evaluate emerging treatment options and to reflect changes in treatment guidelines.

J Manag Care Spec Pharm. 2016;22(12):1437-45

Copyright @2016, Academy of Managed Care Pharmacy. All rights reserved.

\section{What is already known about this subject}

Nearly 4 million persons in the United States are estimated to be chronically infected with hepatitis C virus (HCV), a slow-progressing infection that can lead to cirrhosis, hepatocellular carcinoma, end-stage liver disease, and death over the course of decades.
Direct-acting antivirals (DAAs) have drastically improved sustained virologic response (SVR) rates, tolerability, and shortened treatment durations for HCV compared with older treatment options.

It has been estimated that payers would need $\$ 136$ billion to cover medication costs for all eligible patients with HCV from 2015-2020, of which $\$ 61$ billion would need to be paid by the government; for this reason, some payers restrict access to DAA medications to patients with a fibrosis score of 3-4.

\section{What this study adds}

This study shows that nearly $\$ 42$ million were spent on 322 treatments, resulting in an average cost of $\$ 130,391$ per patient; 269 SVRs were achieved for a mean drug cost per SVR of $\$ 155,662$. The total cost spent on treatments, mean drug cost per patient, and mean drug cost per SVR were all higher for patients with a fibrosis score of 3-4 versus a fibrosis score of 0-2, which is likely because of longer treatment durations, lower SVR rates, and more total treatments with this population.

Mean completed treatment durations were longer for patients with a fibrosis score of 3-4 versus a fibrosis score of 0-2 for all treatment regimens.

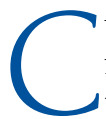
urrent estimates indicate that nearly 4 million persons in the United States are chronically infected with hepati-

tis C virus (HCV) as of 2013. Untreated HCV can lead to cirrhosis, end-stage liver disease, and hepatocellular carcinoma and is the leading cause of liver transplantations in the United States. ${ }^{1}$ A major predictor of serious complications from $\mathrm{HCV}$ is a fibrosis score of F3 or F4 before treatment, a score used to indicate the amount of scarring in the liver. ${ }^{2}$ Successful treatment of HCV has been shown to prevent these complications in addition to reducing mortality and health care costs and improving quality of life. ${ }^{3-5}$

New treatments called direct-acting antivirals (DAAs) came to the market in 2011 and have since improved outcomes considerably by increasing sustained virologic response (SVR) rates, shortening duration of treatment, and improving tolerability compared with older interferon (IFN) regimens. In clinical trials, cure rates exceeded $90 \%$ for many patient populations. ${ }^{6-17}$ Approval of new therapies has spurred frequent revisions to the HCV treatment guidelines authored in colloraboration by the American Association for the Study of Liver Diseases, the Infectious Diseases Society of America, and the International Antiviral Society-USA. ${ }^{18}$ 
Ultimately, the percentage of eligible patients who receive DAA treatment for HCV remains low. In addition to many patients being unaware of their HCV status, lack of knowledge about $\mathrm{HCV}$, social stigma regarding this infection, and medical ineligibility, as well as patient, provider, and medical barriers, contribute to the lack of treatments in the United States. ${ }^{19-21}$ The overwhelming cost of these medications has a significant impact on the health care system. It has been estimated that payers would need $\$ 136$ billion to cover medication costs for all eligible patients with HCV from 2015-2020, of which $\$ 61$ billion would need to be paid by the government. ${ }^{22}$ As a result, some payers are restricting access to only those patients in more advanced stages of disease, in some cases requiring fibrosis scores of $\mathrm{F} 3$ or F4 before covering a DAA medication, and preference is given by many providers to treat patients with more advanced fibrosis. ${ }^{23,24}$

Previous simulation studies in various populations have proposed that treating patients with DAA regimens early in the course of infection, regardless of fibrosis staging may be more cost-effective than restricting access to patients with later fibrosis staging. ${ }^{25-29}$ However, these studies use simulations and projected medical costs rather than estimated actual costs. Real-world drug cost implications of restricting treatment to patients in later stages of infection is unknown. The objective of this study was to describe the drug cost implications and outcomes of treating HCV genotypes 1-4 with DAAs early in the course of infection versus late in the course of infection in a large multisite ambulatory care setting.

\section{Methods}

This study was a retrospective and prospective chart review of patients treated at 36 clinical sites in the state of Massachusetts. Before retrieval of data, the study protocol was approved by the MCPHS University Institutional Review Board. Eligible patients had at least 1 encounter at Atrius Health documented in the electronic medical record (EMR); had a diagnosis of HCV genotype 1, 2, 3, 4, or a mix of these genotypes; and had a prescription for at least 1 of the study medications between May 2011 and October 2015. Atrius Health is a nonprofit alliance of community-based medical groups that provides primary and specialty care to 675,000 adult and pediatric patients across more than 20 site locations in eastern and central Massachusetts. Atrius Health has 29 medical practices, with more than 50 specialties and 725 physicians.

Study medications included telaprevir (TEL), boceprevir (BOC), simeprevir (SIM), sofosbuvir (SOF), ledipasvir/ sofosbuvir (LED/SOF), and ombitasvir/paritaprevir/ritonavir/ dasabuvir (referred to as the 3D regimen). Study medications may have been used in combination or with ribavirin (RBV) and/or IFN. Participants were excluded from the study if they had a diagnosis of HCV genotype 5 or 6 , did not have a documented fibrosis score in the EMR, did not have relevant accessible medical records from an outside facility, did not receive a dose of the study medication (e.g., insurance rejected the claim), or did not have a documented HCV-ribonucleic acid (RNA) at least 12 weeks after completion of therapy in order to test for SVR by the end of data collection.

The primary outcome for the study was to determine the mean drug cost per SVR achieved for patients with a fibrosis score of 0-2 and of 3-4. Secondary outcomes included determining the mean drug cost per SVR achieved for each treatment regimen, determining SVR rates for each treatment regimen, determining SVR rates for patients with fibrosis scores of $0-2$ and 3-4, determining the mean duration of treatment for each treatment regimen, and determining the mean duration of treatment for patients with fibrosis scores of 0-2 and 3-4.

A predetermined sample size of 300 patients was identified based on the anticipated number of patients that would meet inclusion criteria at Atrius Health and was determined adequate for reflecting the local drug cost impact of DAA medications in the given time frame. Eligible patients were identified through the use of the institution's EMR, as well as claims data for accessible payers. If a patient had more than 1 treatment course with a study medication, each treatment course was documented and reflected as a unique patient in the data. For example, a patient may have received treatment with TEL triple therapy in 2011 and then SOF + RBV in 2014. These treatment courses would be reflected as 2 unique patients and regimens in the data. An in-depth chart review was conducted by the primary investigator to obtain the following: patient age, gender, race/ethnicity, body mass index (BMI), past history of treatment, $\mathrm{HCV}$ genotype, most recent fibrosis score before initiation of treatment, human immunodeficiency virus (HIV) history, current HCV treatment regimen, treatment duration, and presence or lack of SVR at least 12 weeks after treatment. Data were collected through April 2016. All statistical analyses, including means, standard deviations, medians, percentages, and cost analyses were conducted by the primary investigator using Microsoft Excel 2010 (Microsoft, Redmond, WA).

If a patient had more than 1 fibrosis score or liver biopsy, results from the most relevant test (most recent before the time of treatment) were recorded. Fibrosis scores were documented according to the following: a fibrosis score of $\mathrm{FO}$ was recorded as 0 ; scores of F1, F0/F1, or F1[F1-2] were recorded as 1 ; scores of F2, F1/F2, F2[F1-2], F2[F2-F3], or F2[F1-F3] were recorded as 2; scores of F3, F2/F3, F3[F2-4], or F3[F3-4] were recorded as 3; and scores of F4, F3/F4, liver biopsy consistent with cirrhosis, or diagnosis of cirrhosis in the EMR were recorded as 4 An algorithm was developed because results were reported differently depending on the specific test used (some tests reported ranges; some reported a probable fibrosis score; and some reported both). If there was only a range of numbers, the algorithm used the highest number in the range (e.g., F2/3=3). If there is a range with a probable fibrosis score, the probable 


\section{FIGURE 1 Study Cohort}

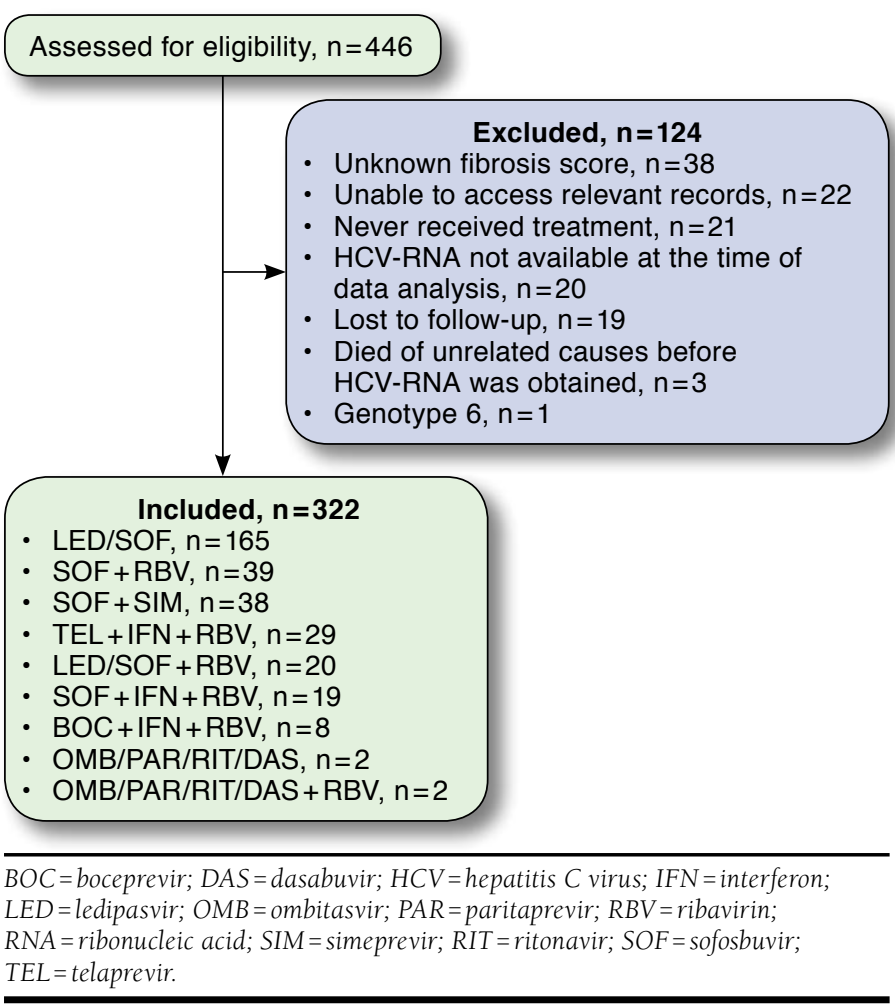

fibrosis score (e.g., F2 [F2-3] =2) was used. The format F2[F2-3] means that a fibrosis score of 2 is probable; however, it could also be a fibrosis score of 3 .

Patients included in the study may have been treated in correspondence with other local institutions. SVR was defined as an undetectable HCV-RNA at least 12 weeks after therapy completion. SVR at 12 weeks is currently used for approval of new treatments. Previous trials used 24 weeks as a marker for SVR; however, 12 weeks has been shown to be an adequate predictor of treatment success with a positive predictive value of $98 \%$ and has been more commonly used in recent trials. ${ }^{30}$ HCV-RNA tests were able to detect viruses with an HCV-RNA of at least $15 \mathrm{IU} / \mathrm{mL}$. Any relapse at least 12 weeks after therapy completion was considered a treatment failure, unless there was proven documentation of reinfection.

Because of the time frame of data collection, as well as frequent delays in starting treatment due to prior authorizations and appeals, a number of patients had not completed their full course of treatments or were pending blood work at the completion of data collection (Figure 1). Additionally, many patients were treated at outside institutions, and blood work was not always accessible in a timely manner. For these reasons, it was determined not to use an intent-to-treat analysis, since this would have underestimated SVR rates in the present study.
All cost analyses were performed using average wholesale price (AWP). Mean drug cost per SVR was calculated using the total cost of study medication (including IFN and RBV) in the numerator accounting for duration of treatment and the total number of SVRs achieved with that regimen in the denominator. Duration of completed treatment was estimated based on the chart review and accounted for early discontinuation of treatment due to adverse drug reactions (ADRs), poor response, or any other reason. If a patient discontinued treatment early for any reason, the duration the patient actually received was used for the cost (but was rounded up to the nearest 4 weeks, since mail-order pharmacies typically send 4 weeks of medication at a time). For example, if a patient stopped treatment at 10 weeks, the cost analysis used 12 weeks because this is most likely the amount paid for by the health care system. If the date of early discontinuation was unknown, 12 weeks was used for early discontinuation because of ADRs with BOC or TEL triple therapy, and 24 weeks was used for early discontinuation because of poor response with BOC or TEL triple therapy. These estimates were based on observations from other treatments, as well as on treatment protocols. Cost analyses only included drug costs for HCV medications and did not take into account cost of adjunctive medications, costs of switching DAA regimens, hospital visits, blood work, complications, or any other medical cost.

\section{Results}

A total of 446 patients were assessed for eligibility, with 124 patients excluded. The most common reasons for exclusion included unknown fibrosis score according to the EMR, inability to access relevant records, patient never receiving treatment with a study medication, and HCV-RNA unavailable at the time of data analysis (Figure 1). Some patients were treated at outside institutions, so not all relevant records were accessible for review, and patients were excluded accordingly. Some patients received valid prescriptions, but claims were rejected by their insurance, and they never received treatment. Some patients were pending blood work at the termination of data collection and were excluded accordingly. A total of 322 patients met inclusion into the study. The majority of patients in this study were older, white males with genotype 1 infection. The mean age was around 60 years, and the mean BMI was $29 \mathrm{~kg} / \mathrm{m}^{2}$. About half of the total population was treatment naïve and half was treatment experienced (Table 1).

During the study, 5 of 322 (1.6\%) patients reported missing doses of their study medications. Reasons given for these missed doses included forgetting a dose, not taking the medication because of a stomach bug, delay in shipment of the medication because of insurance issues, and losing a tablet. Of these patients, 5 of $5(100 \%)$ achieved SVR.

SVR rates with 3D and LED/SOF were 100\% (2/2) and 97.0\% (160/165), respectively. The SVR rate with SOF + RBV was 
Real-World Drug Costs of Treating Hepatitis C Genotypes 1-4 with

Direct-Acting Antivirals: Initiating Treatment at Fibrosis 0-2 and 3-4

\section{TABLE 1 Patient Characteristics}

\begin{tabular}{|c|c|c|c|}
\hline Characteristic & $\begin{array}{c}\text { Total } \\
\mathrm{N}=322\end{array}$ & $\begin{array}{c}\text { Fibrosis } 0-2 \\
\mathrm{n}=116\end{array}$ & $\begin{array}{c}\text { Fibrosis 3-4 } \\
\mathrm{n}=206\end{array}$ \\
\hline Age, years $\pm S D$ & $59.9 \pm 10.6$ & $56.4 \pm 10.6$ & $61.8 \pm 10.5$ \\
\hline \multicolumn{4}{|l|}{ Age, n (\%) } \\
\hline$<45$ years & $26 \quad(8.1)$ & $18(15.5)$ & $8 \quad(3.9)$ \\
\hline $45-54$ years & $36 \quad(11.2)$ & $18(15.5)$ & $18 \quad(8.7)$ \\
\hline $55-65$ years & $180(55.9)$ & $64 \quad(55.2)$ & $116(56.3)$ \\
\hline$>65$ years & $80 \quad(24.8)$ & $16(13.8)$ & $64 \quad(31.1)$ \\
\hline $\begin{array}{l}\text { Born between } 1945 \text { and } 1965 \text {, } \\
\text { n (\%) }\end{array}$ & $264(82.0)$ & $88(75.9)$ & $176(85.4)$ \\
\hline \multicolumn{4}{|l|}{ Race or ethnic group, n (\%) } \\
\hline White & $208(64.6)$ & $78 \quad(67.2)$ & $130(63.1)$ \\
\hline Black or African American & $75(23.3)$ & $22(19.0)$ & $53(25.7)$ \\
\hline Hispanic or Latino & $18 \quad(5.6)$ & $6 \quad(5.2)$ & $12 \quad(5.8)$ \\
\hline Asian & $7 \quad(2.2)$ & $4 \quad(3.4)$ & $3 \quad(1.5)$ \\
\hline Unknown or other & $14 \quad(4.3)$ & $6 \quad(5.2)$ & $8 \quad(3.9)$ \\
\hline Male sex, n (\%) & $224(69.6)$ & $65(56.0)$ & $159(77.2)$ \\
\hline BMI $\left(\mathrm{kg} / \mathrm{m}^{2}\right) \pm \mathrm{SD}$ & $29.0 \pm 7.0$ & $28.1 \pm 7.0$ & $29.5 \pm 7.1$ \\
\hline \multicolumn{4}{|l|}{ Fibrosis score, $\mathrm{n}(\%)^{\mathrm{a}}$} \\
\hline 0 & $13 \quad(4.0)$ & $13(11.2)$ & - \\
\hline 1 & $36 \quad(11.2)$ & $36 \quad(31.0)$ & - \\
\hline 2 & $67(20.8)$ & $67 \quad(57.8)$ & - \\
\hline 3 & $59(18.3)$ & - & $59(28.6)$ \\
\hline 4 & $147(45.7)$ & - & $147(71.4)$ \\
\hline HIV coinfection, n (\%) & $17 \quad(5.3)$ & $2 \quad(1.7)$ & $15 \quad(7.3)$ \\
\hline \multicolumn{4}{|l|}{ Treatment history, n (\%) } \\
\hline Naïve & $164(50.9)$ & $78 \quad(67.2)$ & $86 \quad(41.7)$ \\
\hline Experienced & $158(49.1)$ & $38(32.8)$ & $120(58.3)$ \\
\hline \multicolumn{4}{|l|}{ Genotype, n (\%) } \\
\hline 1 & $275(85.4)$ & $93(80.2)$ & $182(88.3)$ \\
\hline 2 & $25 \quad(7.8)$ & $13(11.2)$ & $12 \quad(5.8)$ \\
\hline 3 & $13 \quad(4.0)$ & $6 \quad(5.2)$ & $7 \quad(3.4)$ \\
\hline 4 & $6 \quad(1.9)$ & $4 \quad(3.4)$ & $2 \quad(1.0)$ \\
\hline Mixed 1/2 & $3(<1.0)$ & - & $3 \quad(1.5)$ \\
\hline \multicolumn{4}{|c|}{$\begin{array}{l}\text { aFibrosis score of F0 was recorded as 0; F1, F0/F1, or F1[F1-2] was recorded as } \\
1 ; \mathrm{F} 2, \mathrm{~F} 1 / \mathrm{F} 2, \mathrm{~F} 2[\mathrm{~F} 1-2], \mathrm{F} 2[\mathrm{~F} 2-\mathrm{F} 3] \text {, or F2[F1-F3] was recorded as } 2 ; \mathrm{F} 3, \mathrm{~F} 2 / \mathrm{F} 3 \text {, } \\
\text { F3[F2-4], or F3[F3-4] was recorded as } 3 \text {; and F4, F3/F4, or liver biopsy consistent } \\
\text { with cirrhosis or diagnosis of cirrhosis in the EMR was recorded as } 4 \text {. } \\
\text { BMI= body mass index; EMR=electronic medical record; HIV=human immuno- } \\
\text { deficiency virus; } \mathrm{kg}=\text { kilogram; } m=\text { meter; } S D=\text { standard deviation. }\end{array}$} \\
\hline
\end{tabular}

92.3\% (36/39); LED/SOF + RBV was 85\% (17/20); SOF + SIM was $73.7 \%$ (28/38); SOF + IFN + RBV was $73.7 \%$ (14/19); $3 \mathrm{D}+\mathrm{RBV}$ was $50 \%(1 / 2)$; TEL + IFN + RBV was $31.0 \%(9 / 29)$; and BOC+IFN + RBV was 25\% (2/8; Table 2). The overall sample sizes for 3D, 3D+RBV, and BOC+IFN+RBV were small, and results should be interpreted accordingly. The overall SVR rate was $83.5 \%$ (269/322) for all patients and 92.2\% (107/116) and $78.6 \%(162 / 206)$ for patients with fibrosis scores of $0-2$ and $3-4$, respectively. The overall SVR rate was $90.5 \%$ (258/285) for all patients and 98.1\% (102/104) and 86.2\% (156/181) for patients with fibrosis scores of 0-2 and 3-4, respectively, when BOC and TEL regimens were excluded.

\section{TABLE 2 SVR Rates}

\begin{tabular}{|c|c|c|c|}
\hline Drugs & $\begin{array}{c}\text { Total, } \\
\mathrm{N}=322 \\
\mathrm{n}(\%)\end{array}$ & $\begin{array}{c}\text { Fibrosis } 0-2 \\
\mathrm{n}=116 \\
\mathrm{n}(\%)\end{array}$ & $\begin{array}{c}\text { Fibrosis 3-4, } \\
\text { n=206 } \\
\text { n (\%) }\end{array}$ \\
\hline $3 \mathrm{D}$ & $2 / 2(100.0)$ & $1 / 1(100.0)$ & $1 / 1(100.0)$ \\
\hline $\mathrm{ED} / \mathrm{SOF}$ & $160 / 165 \quad(97.0)$ & $64 / 65 \quad(98.5)$ & $96 / 100 \quad(96.0)$ \\
\hline $\mathrm{SOF}+\mathrm{RBV}$ & $36 / 39 \quad(92.3)$ & $19 / 19(100.0)$ & $17 / 20 \quad(85.0)$ \\
\hline $\mathrm{LED} / \mathrm{SOF}+\mathrm{RBV}$ & $17 / 20 \quad(85.0)$ & $3 / 3(100.0)$ & $14 / 17 \quad(82.4)$ \\
\hline $\mathrm{SOF}+\mathrm{SIM}$ & $28 / 38 \quad(73.7)$ & $8 / 8(100.0)$ & $20 / 30 \quad(66.7)$ \\
\hline $\mathrm{SOF}+\mathrm{IFN}+\mathrm{RBV}$ & $14 / 19 \quad(73.7)$ & $6 / 7 \quad(85.7)$ & $8 / 12 \quad(66.7)$ \\
\hline $3 \mathrm{D}+\mathrm{RBV}$ & $1 / 2 \quad(50.0)$ & $1 / 1(100.0)$ & $0 / 1$ \\
\hline TEL + IFN + RBV & $9 / 29 \quad(31.0)$ & $5 / 9 \quad(55.6)$ & $4 / 20 \quad(20.0)$ \\
\hline $\mathrm{BOC}+\mathrm{IFN}+\mathrm{RBV}$ & $2 / 8 \quad(25.0)$ & $0 / 3$ & $2 / 5 \quad(40.0)$ \\
\hline Total & $269 / 322 \quad(83.5)$ & $107 / 116 \quad(92.2)$ & $162 / 206 \quad(78.6)$ \\
\hline $\begin{array}{l}\text { Total excluding BOC } \\
\text { and TEL regimens }\end{array}$ & $258 / 285 \quad(90.5)$ & $102 / 104 \quad(98.1)$ & $156 / 181(86.2)$ \\
\hline
\end{tabular}

$3 D=$ ombitasvir/paritaprevir/ritonavir/dasabuvir; $B O C=$ boceprevir; IFN = interferon; $L E D=$ ledipasvir; $R B V=$ ribavirin; $S I=$ simeprevir; $S O F=$ sofosbuvir; $S V R=$ sustained virologic response; TEL=telaprevir.

The mean duration \pm standard deviation of treatment was $15.0 \pm 8.9$ weeks for all patients and $13.1 \pm 8.8$ weeks and $16.1 \pm 8.9$ weeks for patients with fibrosis scores of $0-2$ and $3-4$, respectively. The mean duration of treatment was $13.3 \pm 6.7$ weeks for all patients and $11.8 \pm 6.6$ weeks and $14.1 \pm 6.6$ weeks for patients with fibrosis scores of $0-2$ and 3-4, respectively, when BOC and TEL regimens were excluded. The overall median duration of treatment was 12 weeks, which was consistent with the median duration for all treatment regimens except first generation protease inhibitor regimens.

An estimated total of $\$ 41,873,160$ was spent on 322 regimens for a mean estimated cost of $\$ 130,391 \pm 46,787$ per regimen. Total mean drug cost per SVR was $\$ 155,662$ for all patients with a mean drug cost per SVR of $\$ 122,452$ and $\$ 178,401$ for patients with fibrosis scores of $0-2$ and 3-4, respectively. When BOC and TEL regimens were excluded, the total mean drug cost per SVR was $\$ 147,348$ for all patients, with a mean drug cost per SVR of $\$ 116,579$ and $\$ 167,467$ for patients with fibrosis scores of 0-2 and 3-4, respectively. Mean drug cost per SVR with LED/SOF was $\$ 123,559$; SOF + RBV was $\$ 153,347$; LED/SOF + RBV was $\$ 157,969 ; \mathrm{SOF}+\mathrm{IFN}+\mathrm{RBV}$ was $\$ 184,800 ; \quad \mathrm{BOC}+\mathrm{IFN}+\mathrm{RBV}$ was $\$ 248,640 ; \mathrm{SOF}+\mathrm{SIM}$ was $\$ 251,550$; and TEL+IFN + RBV was $\$ 373,333$ (Table 3). Because of the lack of 3D and 3D + RBV regimens, an adequate cost analysis could not be performed.

\section{Discussion}

Over $80 \%$ of patients in this study were born between 1945 and 1965, which is possibly a result of implementation of CDC recommendations to screen any individual born in this time period. ${ }^{1}$ The majority of patients had a fibrosis score 


\begin{tabular}{|c|c|c|c|c|c|c|c|}
\hline Drugs & $\begin{array}{c}\text { Number } \\
\text { of } \\
\text { Patients } \\
\text { Treated }\end{array}$ & $\begin{array}{l}\text { Mean Drug Cost } \\
\text { per Patient } \pm S D \\
\text { (Median) }\end{array}$ & $\begin{array}{c}\text { Total Mean Drug } \\
\text { Cost per SVR } \\
\text { (Total Drug Cost/ } \\
\text { Number of SVRs } \\
\text { Achieved) }\end{array}$ & $\begin{array}{c}\text { Number } \\
\text { of Patients } \\
\text { Treated } \\
\text { with } \\
\text { Fibrosis } \\
\text { Score } \\
0,1,2\end{array}$ & $\begin{array}{c}\text { Mean Drug Cost } \\
\text { per SVR (Total } \\
\text { Drug Cost/Number } \\
\text { of SVRs Achieved) } \\
\text { for Fibrosis Score } \\
0,1,2\end{array}$ & $\begin{array}{c}\text { Number } \\
\text { of Patients } \\
\text { Treated } \\
\text { with } \\
\text { Fibrosis } \\
\text { Score } 3,4\end{array}$ & $\begin{array}{c}\text { Mean Drug Cost } \\
\text { per SVR (Total } \\
\text { Drug Cost/Number } \\
\text { of SVRs Achieved) } \\
\text { for Fibrosis Score } \\
3,4\end{array}$ \\
\hline LED/SOF & 165 & $\begin{array}{c}119,815 \pm 43,706 \\
(113,400)\end{array}$ & $\begin{array}{c}123,559 \\
(19,769,400 / 160) \\
\end{array}$ & 65 & $\begin{array}{c}100,997 \\
(6,463,800 / 64)\end{array}$ & 100 & $\begin{array}{c}138,600 \\
(13,305,600 / 96)\end{array}$ \\
\hline $\mathrm{SOF}+\mathrm{RBV}$ & 39 & $\begin{array}{c}141,106 \pm 49,130 \\
(104,160)\end{array}$ & $\begin{array}{c}153,347 \\
(5,520,480 / 36)\end{array}$ & 19 & $\begin{array}{c}137,053 \\
(2,604,000 / 19)\end{array}$ & 20 & $\begin{array}{c}171,558 \\
(2,916,480 / 17)\end{array}$ \\
\hline $\mathrm{LED} / \mathrm{SOF}+\mathrm{RBV}$ & 20 & $\begin{array}{c}134,274 \pm 42,775 \\
(116,760)\end{array}$ & $\begin{array}{c}157,969 \\
(2,685,480 / 17)\end{array}$ & 3 & $\begin{array}{c}137,200 \\
(350,280 / 3)\end{array}$ & 17 & $\begin{array}{c}220,500 \\
(2,335,200 / 14)\end{array}$ \\
\hline $\mathrm{SOF}+\mathrm{IFN}+\mathrm{RBV}$ & 19 & $\begin{array}{c}136,168 \pm 44,057 \\
(117,600)\end{array}$ & $\begin{array}{c}184,800 \\
(2,587,200 / 14) \\
\end{array}$ & 7 & $\begin{array}{c}116,760 \\
(823,200 / 6)\end{array}$ & 12 & $\begin{array}{c}166,800 \\
(1,764,000 / 8)\end{array}$ \\
\hline $\mathrm{SOF}+\mathrm{SIM}$ & 38 & $\begin{array}{c}185,353 \pm 29,297 \\
(180,600)\end{array}$ & $\begin{array}{c}251,550 \\
(7,043,400 / 28)\end{array}$ & 8 & $\begin{array}{c}180,600 \\
(1,444,800 / 8)\end{array}$ & 30 & $\begin{array}{c}279,930 \\
(5,598,600 / 20)\end{array}$ \\
\hline $\mathrm{BOCI}+\mathrm{IFN}+\mathrm{RBV}$ & 8 & $\begin{array}{c}62,160 \pm 21,533 \\
(57,960)\end{array}$ & $\begin{array}{c}248,640 \\
(497,280 / 2)\end{array}$ & 3 & $\begin{array}{c}\mathrm{N}^{\mathrm{N}} \mathrm{A}^{\mathrm{a}} \\
(140,280 / 0)\end{array}$ & 5 & $\begin{array}{c}178,500 \\
(357,000 / 2)\end{array}$ \\
\hline TEL + IFN + RBV & 29 & $\begin{array}{c}120,352 \pm 19,836 \\
(113,400)\end{array}$ & $\begin{array}{c}373,333 \\
(3,360,000 / 9)\end{array}$ & 9 & $\begin{array}{c}188,160 \\
(1,071,000 / 5) \\
\end{array}$ & 20 & $\begin{array}{c}604,800 \\
(2,419,200 / 4)\end{array}$ \\
\hline Total $^{\mathrm{b}}$ & 322 & $\begin{array}{c}130,391 \pm 46,787 \\
(113,400)\end{array}$ & $\begin{array}{c}155,662 \\
(41,873,160 / 269)\end{array}$ & 116 & $\begin{array}{c}122,452 \\
(13,102,320 / 107)\end{array}$ & 206 & $\begin{array}{c}178,401 \\
(28,901,040)\end{array}$ \\
\hline $\begin{array}{l}\text { Total excluding TEL and BOC } \\
\text { regimens }{ }^{b}\end{array}$ & 285 & $\begin{array}{c}133,328 \pm 45,930 \\
(113,400)\end{array}$ & $\begin{array}{c}147,348 \\
(38,015,880 / 258)\end{array}$ & 104 & $\begin{array}{c}116,579 \\
(11,891,040 / 102)\end{array}$ & 181 & $\begin{array}{c}167,467 \\
(26,124,840 / 156)\end{array}$ \\
\hline $\begin{array}{l}\text { Total excluding all 24-week } \\
\text { regimens }\end{array}$ & 281 & $\begin{array}{c}116,540 \pm 30,266 \\
(113,400)\end{array}$ & $\begin{array}{c}140,985 \\
(32,426,520 / 230) \\
\end{array}$ & 109 & $\begin{array}{c}116,256 \\
(11,625,600 / 100)\end{array}$ & 172 & $\begin{array}{c}161,009 \\
(20,931,120 / 130) \\
\end{array}$ \\
\hline $\begin{array}{l}\text { Total excluding all } 24 \text {-week regimens } \\
\text { and TEL and BOC regimens }{ }^{b}\end{array}$ & 244 & $\begin{array}{c}117,870 \pm 46,787 \\
(113,400)\end{array}$ & $\begin{array}{c}130,453 \\
(28,569,240 / 219) \\
\end{array}$ & 97 & $\begin{array}{c}109,624 \\
(10,414,320 / 95) \\
\end{array}$ & 147 & $\begin{array}{c}146,411 \\
(18,154,920 / 124) \\
\end{array}$ \\
\hline
\end{tabular}

Note: All costs are in U.S. dollars and are calculated using average wholesale price. Cost analyses only include cost of HCV medications, not adjunctive medications,

hospital costs, or projected medical costs.

${ }^{a}$ No patients achieved SVR with BOC + IFN + RBV with fibrosis score 0-2, so a mean drug cost per SVR could not be calculated.

$b 3 D$ and $3 D+R B V$ are included in the totals, but only 2 patients were treated with each regimen (4 total), so an individual cost analysis for these regimens was not completed. $3 D=$ ombitasvir/paritaprevir/ritonavir/dasabuvir; $B O C=$ boceprevir; $H C V=$ hepatitis $C$ virus; $I F N=$ interferon; $L E D=$ ledipasvir; $N / A=$ not available; $R B V=$ ribavirin; $S I M=$ simeprevir; $S O F=$ sofosbuvir; SVR = sustained virologic response; $S D=$ standard deviation; $T E L=$ telaprevir.

of $3-4$, accounting for over $60 \%$ of treatments, which likely reflects payer restrictions and provider preference to treat this population with higher priority. Patients with a fibrosis score of 3-4 were older, had a higher mean BMI, were more likely to be coinfected with HIV, more likely to be genotype 1, more likely to be male, and more likely to be treatment experienced compared with patients who had fibrosis scores of 0-2. Differences in patient characteristics may have affected SVR rates. Increased age and HIV coinfection have been shown to be independent risk factors for progression of fibrosis in intravenous drug users in previous studies, which possibly explains the distribution seen in this study ${ }^{31,32}$ Among patients with HIV coinfection, 100\% (17/17) successfully achieved SVR; therefore, HIV coinfection did not appear to affect SVR rates in this study, regardless of fibrosis score.

In this study, only 5 (1.6\%) patients reported missing doses of their study medication or taking the medication incorrectly. Although adherence was addressed and strongly encouraged during many follow-up visits and phone encounters, this number is likely an underestimation of the actual number of patients who missed their medication doses. This study was observational with multiple sites; therefore, there was no set protocol in place to assess for adherence during every encounter. It is unlikely that adherence was addressed and reported for every patient included in the study, and the actual reporting of nonadherence is underestimated. Other methods for assessing adherence were considered and are addressed in the Limitations section.

For patients with a fibrosis score of 0-2, LED/SOF had the shortest treatment duration of $10.5(\mathrm{SD} \pm 6.6)$ weeks, likely because of the use of 8 -week regimens in qualifying patients (Table 4). Criteria for LED/SOF 8-week treatment is genotype 1 treatment-naive, baseline HCV-RNA level of less than 6 million $\mathrm{IU} / \mathrm{mL}$, without compensated cirrhosis.

Because of low SVR rates and longer duration of treatment (with an average completed duration of 28.3 weeks), BOC and TEL regimens had a relatively high drug cost per SVR at 


\begin{tabular}{|c|c|c|c|}
\hline Drugs & $\begin{array}{l}\text { Total } \\
\mathrm{N}=322 \\
\text { Weeks }\end{array}$ & $\begin{array}{c}\text { Fibrosis Score } \\
0,1,2 \\
\mathbf{n}=116 \\
\text { Weeks }\end{array}$ & $\begin{array}{c}\text { Fibrosis Score } \\
3,4 \\
\mathbf{n}=206 \\
\text { Weeks }\end{array}$ \\
\hline LED/SOF & $12.7 \pm 6.7(12)$ & $10.5 \pm 6.6(12)$ & $14.1 \pm 6.6(12)$ \\
\hline $\mathrm{SOF}+\mathrm{RBV}$ & $16.3 \pm 5.8(12)$ & $15.8 \pm 6.1(12)$ & $16.7 \pm 4.8(12)$ \\
\hline $\mathrm{LED} / \mathrm{SOF}+\mathrm{RBV}$ & $14.1 \pm 6.0(12)$ & $12.0 \pm 0 \quad(12)$ & $14.1 \pm 6.0$ \\
\hline SOF + SIM & $12.3 \pm 2.6(12)$ & $12.0 \pm 0 \quad(12)$ & $12.4 \pm 5.8(12)$ \\
\hline $\mathrm{SOF}+\mathrm{IFN}+\mathrm{RBV}$ & $13.9 \pm 5.8(12)$ & $12.0 \pm 0 \quad$ (12) & $15.0 \pm 5.8(12)$ \\
\hline TEL+IFN + RBV & $29.0 \pm 8.6(24)$ & $28.0 \pm 8.6(24)$ & $29.4 \pm 8.4(24)$ \\
\hline $\mathrm{BOC}+\mathrm{IFN}+\mathrm{RBV}$ & $27.0 \pm 8.9(24)$ & $16.0 \pm 3.7(12)$ & $33.6 \pm 8.9(36)$ \\
\hline Totala & $15.0 \pm 8.9(12)$ & $13.1 \pm 8.8(12)$ & $16.1 \pm 8.9(12)$ \\
\hline $\begin{array}{l}\text { Total excluding TEL } \\
\text { and BOC regimens }{ }^{\mathrm{a}} \\
\end{array}$ & $13.3 \pm 6.7(12)$ & $11.8 \pm 6.6(12)$ & $14.1 \pm 6.6(12)$ \\
\hline \multicolumn{4}{|c|}{$\begin{array}{l}\text { aTwo } 12 \text {-week } 3 D \text { regimens and two } 12 \text {-week } 3 D+R B V \text { regimens are included in } \\
\text { the totals. Because of the small number of treatments, these regimens were not } \\
\text { included as individual rows in the chart. } \\
B O C=\text { boceprevir; } I F N=\text { interferon; } L E D=\text { ledipasvir; } R B V=\text { ribavirin; } \\
S I M=\text { simeprevir; } S O F=\text { sofosbuvir; } S D=\text { standard deviation; } T E L=\text { telaprevir. }\end{array}$} \\
\hline
\end{tabular}

$\$ 248,640$ and $\$ 373,333$, respectively, compared with other regimens. Sethi et al. (2015) demonstrated a mean cost per SVR of $\$ 172,889$ for all patients and a mean cost per SVR of $\$ 266,670$ for patients with cirrhosis when treated with firstgeneration protease inhibitors. ${ }^{33}$ Patients in the study had an SVR of $48.5 \%$, and hospital costs were included in addition to drug costs. ${ }^{33}$ Bichoupan et al. (2014) found a median cost per SVR of $\$ 189,338$ for patients treated with TEL triple therapy, with an overall SVR rate of 44\%. ${ }^{34}$ The Bichoupan et al. study also took into account the cost of lab tests, professional fees, and ADR management; however, these costs accounted for less than $6 \%$ of total costs. ${ }^{34}$ The cost analysis in the present study did not account for hospital costs, lab tests, ADR management (including erythropoiesis-stimulating agents or blood transfusion), or cost of additional office visits/phone encounters and underestimates the total cost per SVR; inclusion of these incremental costs would result in slight increases in total cost per SVR. This study used AWP to determine drug costs, while Sethi et al. used wholesale acquisition cost, and Bichoupan et al. used data from Medicare reimbursement databases, RED BOOK, and the Healthcare Cost and Utilization Project database. ${ }^{33,34}$ Differences in medication costs used also accounts for the differences with this study and previous cost analysis studies.

LED/SOF had the lowest mean drug cost per SVR at $\$ 123,559$, primarily because of higher SVR rates and shorter duration of treatment, compared with other regimens. The overall SVR rate for LED/SOF regimens was $97.0 \%$. This SVR rate included all patient groups, including treatment-naïve and experienced patients and those with and without cirrhosis and HIV coinfection. The SVR rate with LED/SOF was higher for patients with a fibrosis score of $0-2$ at $98.5 \%$ than for patients with a fibrosis score of 3-4 at 96.0\%. The SVR rate found in this study is similar to that found in clinical trials, which ranges from 94\%-99\%, depending on duration of treatment and patient population. ${ }^{6-8}$ Among genotype 1 treatment-naive patients treated in this study with LED/SOF 8 -week regimens, the SVR rate was $100 \%$ (32/32), with a mean drug cost per SVR of $\$ 75,600$. Among patients treated for 12 weeks, the SVR rate was $94.4 \%$ (34/36), with a mean drug cost per SVR of $\$ 120,071$. Although this study had a smaller sample size than other clinical trials, the results suggest that using 8 weeks of LED/SOF for appropriate genotype 1 treatment-naive patients without cirrhosis may be a viable option and may result in lower drug costs than 12-week regimens.

A previous simulation study in genotype 1 treatment-naive patients concluded that treating patients earlier in the course of infection resulted in better outcomes and was more costeffective than waiting, but this course of action also increased the total number of health care dollars spent. ${ }^{12}$ Younossi et al. (2015) used a hybrid decision-tree and Markov state-transition model and found that initiating treatment in patients at earlier stages of fibrosis reduced mean cost per SVR and long-term costs for genotype 1 patients. ${ }^{35}$ Their model also demonstrated that LED/SOF was more cost-effective than all comparator treatments. ${ }^{35}$ The present study aimed to determine the mean drug cost per SVR for treating patients at fibrosis scores of 0-2 and 3-4 in patients with genotypes 1-4. The mean drug cost per SVR was 30\% lower for patients with a fibrosis score of $0-2$ versus 3-4, which was maintained with the exclusion of BOC and TEL regimens. This cost difference resulted primarily from a lower SVR rate for patients with a fibrosis score of 3-4 and longer duration of treatment for patients with cirrhosis. The mean drug cost per SVR for patients with a fibrosis score of $0-2$ was lower for all treatments regimens, indicating that this cost difference is not the result of poor outcomes or overuse of one particular regimen.

In the past, 24-week regimens were used more for patients with cirrhosis than they are currently and contributed significantly to the higher cost for treating these patients. A 24-week regimen costs twice that of a 12 -week regimen and 3 times as much as an 8-week regimen and can quickly raise overall drug costs, regardless of effectiveness. A decrease in the use of 24-week regimens after 2015 can be seen in the prescribing patterns of this study, which is consistent with guideline changes that were made to allow the option for shorter treatment regimens. A separate cost analysis was completed, which excluded all 24-week regimens in order to determine the effect on cost. After removing all 24-week regimens, the mean drug cost per SVR for patients with a fibrosis score of 0-2 was $\$ 116,256$; $\$ 161,009$ for patients with a fibrosis score of $3-4$; and $\$ 109,624$ and $\$ 146,411$ when BOC and TEL regimens were excluded. With the removal of all 24-week regimens, this represented a $25 \%$ cost difference between patients with 
fibrosis scores of 0-2 and 3-4. Some 24-week regimens are still recommended by guidelines; therefore, this additional cost analysis is not fully reflective of best practice and is only used as a demonstration. This analysis does not account for health care costs for hepatocellular carcinoma; liver transplantations; decompensated cirrhosis; or procedures, additional lab work, and additional office visits that may be avoided by treating patients earlier in the course of infection.

Results from this study will help to influence future decisions. A number of factors not measured in this study influence treatment choice, outcomes, and cost and should be taken into consideration. Among these are genotype and subgenotype, baseline RNA, presence of decompensated cirrhosis, presence of hepatocellular carcinoma, liver transplantation, renal impairment/dialysis, acute versus chronic infection, pill burden and regimen complexity, payer and organization formulary, and availability of medication.

Results and analyses from this study may not be generalizable to all other geographic regions. Genotype 1 accounted for over $80 \%$ of infections in this study. The distribution of genotype 1 has been estimated at $70 \%$ for other studies. ${ }^{4,36} \mathrm{LED} / \mathrm{SOF}$ prescriptions accounted for over half of the prescriptions in this study, which may vary from other areas based on provider and payer preferences and genotype distributions. Only 5.3\% of patients in this study were coinfected with HIV, which is lower than other studies that have demonstrated coinfection rates ranging from $11 \%-34 \% .32,34$ Distribution of fibrosis scores may also vary from other regions, since this was primarily driven by prior authorization criteria for local payers and provider preference.

\section{Limitations}

This study had several limitations that should be considered. First, this study was a retrospective and prospective chart review and was completely observational and descriptive in nature. It was not designed to directly compare treatment regimens or specific patient populations with one another. Some patient characteristics varied between groups, which may have affected results.

Second, HCV treatment guidelines have changed frequently from 2011 to 2016, so these cost analyses may not represent current best practices. Separate analyses that excluded BOC and TEL regimens, as well as 24-week regimens were used to mimic the current standard of treatment; however, this may not fully account for all guideline changes. New agents were approved at the end of 2015 and early 2016 and were not captured because of the time frame of data collection.

Third, measuring fibrosis has a number of limitations, including use of a variety of tests that are not $100 \%$ equivalent or $100 \%$ accurate. Among these tests include standard liver biopsy, FibroMeter, Fibroscan, Fibrosure, Fibrotest, Fibrospect, and Hepascore. These tests use ultrasound technology or take into account direct or indirect markers of liver fibrosis, using different techniques and are not interchangeable. ${ }^{31}$ Although these tests are accurate for determining cirrhosis (F4) and detecting a lack of fibrosis (F0), they are not as accurate for determining in-between stages, and there are also discrepancies between them. ${ }^{37-40}$ A number of variables can affect reproducibility of fibrosis staging, including steatosis, increased BMI, food consumption, and lower degrees of fibrosis.1-44 Grouping patients into fibrosis 0-2 and 3-4 may have reduced the effect of these inaccuracies; however, this limitation could not be fully overcome. The most common tests used in this study were Fibrosure and Fibrometer; however, the test used was largely driven by payer preference and preference of the treatment site.

Fourth, fibrosis scores may have been underestimated if the patient had undergone fibrosis testing a significant amount of time before starting treatment. In most cases, payers required a recent fibrosis score within a specified time frame (e.g., 6-12 months), but this was not always the case. Some patients had a fibrosis test several years before initiation of treatment, possibly underestimating the true level of fibrosis in their livers during the time of treatment. Fifth, patients with unknown fibrosis scores and those lost to follow-up were excluded from the study, which could lead to potential bias. Excluding patients lost to follow-up and patients with unknown HCV-RNA at the end of data collection may have led to an overestimation of the benefit of DAA regimens in this study.

Finally, this study used patient reports to assess nonadherence to medications, which likely underestimated the number of patients who missed doses or took their medications incorrectly. Other mechanisms for assessing adherence were considered but were not used because of anticipated inaccuracies. Many specialty pharmacies mail prescriptions to patient home addresses on a predetermined schedule; therefore, claims data would have showed $100 \%$ adherence in many cases if used as a marker for adherence. Many patients underwent the prior authorization process to obtain their medications weeks or months before their appointments to initiate treatment, so using the date when a prescription was written in the EMR as the initiation date would also be inaccurate.

\section{Conclusions}

This study demonstrated a mean drug cost per SVR of $\$ 155,662$ in all patients, with a mean drug cost per SVR of $\$ 122,452$ and $\$ 178,401$ for patients with fibrosis scores of $0-2$ and 3-4, respectively (based on AWP). SVR rates were $83.5 \%$ (269/322) for all patients and 92.2\% (107/116) and 78.6\% (162/206) for patients with fibrosis scores of $0-2$ and $3-4$, respectively. Patients with advanced fibrosis were older, had a higher mean BMI, were more likely to be coinfected with HIV, more likely to be genotype 1 , more likely to be male, and more likely to be treatment experienced. Knowledge about drug costs and 
outcomes may influence future decisions. Further research is needed to determine the effect of newer treatment options and changes to treatment guidelines.

\section{Authors}

TIMOTHY A. BACH, PharmD, and KATHY ZAIKEN, PharmD, MCPHS University, Boston, Massachusetts.

AUTHOR CORRESPONDENCE: Timothy A. Bach, PharmD, BayCare Health System, St. Anthony's Hospital, 1200 7th Ave. N St., Petersburg,FL 33705. E-mail: timothy.bach@baycare.org.

\section{DISCLOSURES}

No outside funding supported this study. The authors report no conflicts of interest.

Data in this study were presented as a poster at the ASHP Midyear Clinical Meeting; New Orleans, Louisiana; December 9, 2015; at the Massachusetts Society of Health-System Pharmacists Annual Meeting; Newton, Massachusetts; April 12, 2016; and at Eastern States Conference for Pharmacy Residents and Preceptors; Hershey, Pennsylvania; May 2, 2016.

Study concept and design was primarily contributed by Bach, along with Zaiken. Bach took the lead in data collection, data interpretation, and preparation of the manuscript, along with Zaiken.

\section{ACKNOWLEDGMENTS}

The authors acknowledge Seth Robin, MBA, Atrius Health, for retrieving data and Gary Tataronis, MS, MCPHS University, for employing statistical methods.

\section{REFERENCES}

1. Centers for Disease Control and Prevention. Hepatitis C FAQs for health professionals. March 11, 2016. Available at: http://www.cdc.gov/hepatitis/ hcv/hcvfaq.htm\#sectionl. Accessed October 13, 2016.

2. Xu F, Moorman AC, Tong X, et al. All-cause mortality and progression risks to hepatic decompensation and hepatocellular carcinoma in patients infected with hepatitis C virus. Clin Infect Dis. 2016;62(3):289-97.

3. Gordon SC, Hamzeh FM, Pockros PJ, et al. Hepatitis C virus therapy is associated with lower health care costs not only in noncirrhotic patients but also in patients with end-stage liver disease. Aliment Pharmacol Ther. 2013;38(7):784-93

4. van der Meer AJ, Veldt BJ, Feld JJ, et al. Association between sustained virological response and all-cause mortality among patients with chronic hepatitis $C$ and advanced hepatic fibrosis. JAMA. 2012;308(24):2584-93.

5. Smith-Palmer J, Cerri K, Valentine W. Achieving sustained virologic response in hepatitis C: a systematic review of the clinical, economic and quality of life benefits. BMC Infect Dis. 2015;15:19.

6. Afdhal N, Zeuzem S, Kwo P, et al. Ledipasvir and sofosbuvir for untreated HCV genotype 1 infection. N Engl J Med. 2014;370(20):1889-98

7. Kowdley KV, Gordon SC, Reddy KR, et al. Ledipasvir and sofosbuvir for 8 or 12 weeks for chronic HCV without cirrhosis. N Engl J Med. 2014;370(20):1879-88

8. Afdhal N, Reddy KR, Nelson DR, et al. Ledipasvir and sofosbuvir for previously treated HCV genotype 1 infection. N Engl J Med. 2014;370(16):1483-93.

9. Lawitz E, Mangia A, Wyles D, et al. Sofosbuvir for previously untreated chronic hepatitis C infection. N Engl J Med. 2013;368(20):1878-87.
10. Jacobson IM, Gordon SC, Kowdley KV, et al. Sofosbuvir for hepatitis C genotype 2 or 3 in patients without treatment options. N Engl J Med. 2013;368(20):1867-77.

11. Zeuzem S, Dusheiko GM, Salupere R, et al. Sofosbuvir and ribavirin in HCV genotypes 2 and 3. N Engl J Med. 2014;370(21):1993-2001.

12. Feld JJ, Kowdley KV, Coakley E, et al. Treatment of HCV with ABT-450/ rombitasvir and dasabuvir with ribavirin. N Engl J Med. 2014;370(17):1594-603.

13. Ferenci P, Bernstein D, Lalezari J, et al. ABT-450/r-ombitasvir and dasabuvir with or without ribavirin for HCV. N Engl J Med. 2014;370(21):1983-992.

14. Poordad F, Hezode C, Trinh R, et al. ABT-450/r-ombitasvir and dasabuvir with ribavirin for hepatitis $C$ with cirrhosis. $N$ Engl J Med. 2014;370(21):1973-82.

15. Kwo P, Gitlin N, Nahass R, et al. Simeprevir plus sofosbuvir (12 and 8 weeks) in HCV genotype l-infected patients without cirrhosis: OPTIMIST-1, a phase 3, randomized study. Hepatology. 2016;64(2):370-80.

16. Foster GR, Pianko S, Brown A, et al. Efficacy of sofosbuvir plus ribavirin with or without peginterferon-alfa in patients with hepatitis $C$ virus genotype 3 infection and treatment-experienced patients with cirrhosis and hepatitis C virus genotype 2 infection. Gastroenterology. 2015;149(6):1462-70.

17. Kohli A, Kapoor R, Sims Z, et al. Ledipasvir and sofosbuvir for hepatitis C genotype 4: a proof-of-concept, single-centre, open-label phase 2 a cohort study. Lancet Infect Dis. 2015;15(9):1049-54.

18. American Association for the Study of Liver Diseases, Infectious Diseases Society of America, International Antiviral Society-USA. HCV guidance: recommendations for testing, managing, and treating HCV. April 25, 2016. Available at: www.hcvguidelines.org. Accessed October 13, 2016.

19. Marinho RT, Barreira DP. Hepatitis C, stigma and cure. World J Gastroenterol. 2013;19(40):6703-09.

20. North CS, Hong BA, Adewuyi SA, et al. Hepatitis C treatment and SVR: the gap between clinical trials and real-world treatment aspirations. Gen Hosp Psychiatry. 2013;35(2):122-28.

21. Papatheodoridis G, Hatzakis A. Public health issues of hepatitis $C$ virus infection. Best Pract Res Clin Gastroenterol. 2012;26(4):371-80.

22. Chhatwal J, Kanwal F, Roberts MS, Dunn MA. Cost-effectiveness and budget impact of hepatitis $C$ virus treatment with sofosbuvir and ledipasvir in the United States. Ann Intern Med. 2015;162(6):397-406.

23. Rosenthal ES, Graham CS. Price and affordability of direct-acting antiviral regimens for hepatitis $C$ virus in the United States. Infect Agent Cancer. 2016;11:24.

24. Canary LA, Klevens RM, Holmberg SD. Limited access to new hepatitis $\mathrm{C}$ virus treatment under state Medicaid programs. Ann Intern Med. 2015;163(3):226-28.

25. Younossi ZM, Singer ME, Mir HM, Henry L, Hunt S. Impact of interferon free regimens on clinical and cost outcomes for chronic hepatitis $C$ genotype 1 patients. J Hepatol. 2014;60(3):530-37.

26. Chahal HS, Marseille EA, Tice JA, et al. Cost-effectiveness of early treatment of hepatitis $C$ virus genotype 1 by stage of liver fibrosis in a US treatment-naive population. JAMA Intern Med. 2016;176(1):65-73.

27. Buti M, Domínguez-Hernández R, Oyagüez I, Casado MÁ. [Cost-effectiveness analysis of sofosbuvir, peginterferon and ribavirin in patients with chronic hepatitis C: early treatment in the initial stage of fibrosis vs. delayed treatment in advanced fibrosis]. Gastroenterol Hepatol. 2016;39(7):449-57. [Article in Spanish]

28. Chidi AP, Rogal S, Bryce CL, et al. Cost-effectiveness of new antiviral regimens for treatment-naive U.S. veterans with hepatitis C. Hepatology. 2016;63(2):428-36.

29. Chidi AP, Bryce CL, Donohue JM, et al. Economic and public health impacts of policies restricting access to hepatitis $C$ treatment for Medicaid patients. Value Health. 2016;19(4):326-34. 
30. Saludes V, González V, Planas R, Seeff LB. Tools for the diagnosis of hepatitis $C$ virus infection and hepatic fibrosis staging. World J Gastroenterol. 2014;20(13):3431-42.

31. de Lédinghen V, Barreiro P, Foucher J, et al. Liver fibrosis on account of chronic hepatitis $\mathrm{C}$ is more severe in HIV-positive than HIV-negative patients despite antiretroviral therapy. J Viral Hepat. 2008;15(6):427-33.

32. Kirk GD, Mehta SH, Astemborski J, et al. HIV, age, and the severity of hepatitis $C$ virus-related liver disease: a cohort study. Ann Intern Med. 2013;158(9):658-66.

33. Sethi N, Tapper EB, Vong A, Sethi S, Rourke M, Afdhal NH. Direct costs of first-generation protease inhibitors for the treatment of genotype 1 chronic hepatitis C viral infection. J Viral Hepat. 2015;22(12):974-76.

34. Bichoupan K, Martel-Laferriere V, Sachs D, et al. Costs of telaprevirbased triple therapy for hepatitis C: $\$ 189,000$ per sustained virological response. Hepatology. 2014;60(4):1187-95.

35. Younossi ZM, Park H, Saab S, Ahmed A, Dieterich D, Gordon SC. Cost-effectiveness of all-oral ledipasvir/sofosbuvir regimens in patients with chronic hepatitis $C$ virus genotype 1 infection. Aliment Pharmacol Ther. 2015;41(6):544-63.

36. Manos MM, Shvachko VA, Murphy RC, Arduino JM, Shire NJ. Distribution of hepatitis $C$ virus genotypes in a diverse US integrated health care population. J Med Virol. 2012;84(11):1744-50.

37. Boursier J, Bertrais S, Oberti F, et al. Comparison of fibrosis degree classifications by liver biopsy and non-invasive tests in chronic hepatitis $\mathrm{C}$. BMC Gastroenterol. 2011;11:132.
38. Poynard T, de Ledinghen V, Zarski JP, et al. Relative performances of FibroTest, Fibroscan, and biopsy for the assessment of the stage of liver fibrosis in patients with chronic hepatitis C: a step toward the truth in the absence of a gold standard. J Hepatol. 2012;56(3):541-48.

39. Calvaruso V, Cammà C, Di Marco V, et al. Fibrosis staging in chronic hepatitis C: analysis of discordance between transient elastography and liver biopsy. J Viral Hepat. 2010;17(7):469-74.

40. Chou R, Wasson N. Blood tests to diagnose fibrosis or cirrhosis in patients with chronic hepatitis $C$ virus infection: a systematic review. Ann Intern Med. 2013;158(11):807-20

41. Fraquelli M, Rigamonti C, Casazza G, et al. Reproducibility of transient elastography in the evaluation of liver fibrosis in patients with chronic liver disease. Gut. 2007;56(7):968-73.

42. Arena U, Lupsor Platon M, Stasi C, et al. Liver stiffness is influenced by a standardized meal in patients with chronic hepatitis $C$ virus at different stages of fibrotic evolution. Hepatology. 2013;58(1):65-72. Available at: http://online library.wiley.com/doi/10.1002/hep.26343/epdf. Accessed October 13, 2016.

43. Berzigotti A, de Gottardi A, Vukotic R, et al. Effect of meal ingestion on liver stiffness in patients with cirrhosis and portal hypertension. PLoS One. 2013;8(3):e58742. Available at: http://www.ncbi.nlm.nih.gov/pmc/articles/ PMC3592829/pdf/pone.0058742.pdf. Accessed October 13, 2016.

44. Wong GL. Update of liver fibrosis and steatosis with transient elastography (Fibroscan). Gastroenterol Rep (Oxf). 2013;1(1):19-26. Available at: http:// www.ncbi.nlm.nih.gov/pmc/articles/PMC3941434/pdf/got007.pdf. Accessed October 13, 2016 